\title{
UNCOMMON PRESENTATION OF ANEURYSMAL BONE CYST IN SPINE INVOLVING VERTEBRAL BODY
}

Shrishail Patil ${ }^{1}$, Santosh Kumar ${ }^{2}$, Sanjeev Chhabra ${ }^{3}$

\section{HOW TO CITE THIS ARTICLE:}

Shrishail Patil, Santosh Kumar, Sanjeev Chhabra. "Uncommon Presentation of Aneurysmal Bone Cyst in Spine Involving Vertebral Body". Journal of Evolution of Medical and Dental Sciences 2015; Vol. 4, Issue 08, January 26; Page: 1394-1397, DOI: 10.14260/jemds/2015/195

INTRODUCTION: Aneurysmal bone cyst of the spine was first described by Jaffè et al in 1942. An aneurysmal bone cyst (ABC) is a non-neoplastic expansile and locally destructive highly vascular bone lesion characterized by channels or spaces filled with blood and separated by fibrous septa. It usually involves long bones. Its occurrence in spine is rare, and usually involves posterior elements, while involvement of body is very rare. MRI and CT are the imaging modalities of choice in the diagnosis of bone cysts in the spine. Although regarded as benign tumors, ABCs can be locally aggressive, causing profound destruction of their encasing bones and pathological fractures, as well as compression of adjacent vital tissues from their rapid expansion. For this reason, ABCs of the spine, due to their close proximity to the spinal cord and nerve roots, warrant special attention and present a unique clinical challenge. We are reporting this case with $A B C$ of thoracic spine involvement which was mainly involving the body.

CASE SUMMARY: A 37 year old male from Gulbarga presented to our hospital with complaint of pain in dorsolumbar region for 4 weeks. No history of weakness in both lower limbs, fever, trauma, pulmonary tuberculosis. Patient was referred to radiology department for evaluation.

X-RAY (A. P \& Lateral) revealed expansile lytic lesion noted involving D9 vertebral body with poorly definable right pedicle, reduced intervertebral space between D8-D9.

On further evaluation NECT showed expansile, well defined lytic lesion in D9 vertebral body with extension into bilateral pedicles, right transverse process with thinned out cortex with areas of breach in cortex on right side, with narrow zone of transition and minimal height reduction of D9 vertebral body.

MRI spine showed focal lesion is seen in the D9 vertebral body. This lesion is expansile, and is cystic appearing, hypointense on T1WI and hyperintense on T2 weighted images. It shows evidence of fluid levels within it. There is minimal height reduction of this body, with this lesion extending into the bilateral pedicles and right transverse process as well. Minimal posterior convexity of this lesion into the spinal canal is seen. This is seen to abut the anterior subarachnoid space.

He underwent lateral extracavitary approach and decompression and fixation. The histopathology of post-surgical resection bone biopsy from D9 vertebra studied section reveals blood filled spaces, separated by septae. The lining of septum shows fibro-osteoid. Large areas of haemorrhage and congested vascular spaces are noted, consistent with aneurysmal bone cyst.

DISCUSSION: $\mathrm{ABC}$ is a benign bone lesion of unknown origin. It is a relatively rare lesion that represents $1.4 \%-2.3 \%$ of primary bone tumors. The spine is involved in $3 \%-20 \%$ of cases.(1,2)

$\mathrm{ABC}$ usually occurs between the ages of 5 and 20 years but can manifest at any age. There may be a slight female predilection.(2)

WHO definition is "benign cystic lesions of bone composed of blood filled spaces separated by connective tissue septa containing fibroblasts, osteoclast type giant cells and reactive woven bone."(3) 
It usually involves long bones such as the femur, tibia or humerus but can also occur in the pelvis and spine. Reportedly, the lumbar spine is the most commonly affected area (40\%-45\%) followed by the cervical (30\%) and the thoracic (25\%-30\%) spine, with the posterior elements (Laminae, pedicles, and spinous and transverse processes) more commonly involved than the vertebral bodies (Anterior elements). $(4,5)$

Vertebral body involvement is not frequent; however, when present, it is usually associated with an already existing neural arch lesion.(6)

$A B C$ 's are divided into primary and secondary types. The primary type normally occurs without being associated with another primary bone tumour. The secondary lesions are associated with other tumorous lesions which may be malignant or benign. ${ }^{(7)}$

Despite being benign, they can be locally expansive and destructive, and can result in pathological fractures of the vertebrae and neurological complications. ${ }^{(8,9)}$

Due to their proximity to the spinal cord and nerve roots, rapid expansion and/or pathological fractures can result in compressive phenomena and neurological symptoms, which can range from mild radiculopathies to overt paraparesis.

The three main hypotheses reported in the literature propose that the lesion is the result of either the improper repair of a traumatic subperiosteal hemorrhage, a vascular disturbance of the bone, or hemorrhage into a preexisting lesion.

MRI and CT are the imaging modalities of choice in the diagnosis of bone cysts in the spine. Computer tomography shows an expansile lytic lesion in the posterior elements, which may involve the vertebral body, soft tissue and adjacent vertebrae and ribs. Septa, lobulation and fluid-fluid levels are very suggestive of an $\mathrm{ABC}$ on $\mathrm{CT}$ and MR imaging.

Fluid-fluid levels within ABCs are indicative of hemorrhage with sedimentation and are better demonstrated with MR imaging.

On T1-weighted images, they may have increased signal intensity due to methemoglobin in either the dependent or nondependent component.

Gadolinium-based contrast material injection demonstrates smooth enhancement of the internal septa within ABCs. Other areas usually show high signal intensity on T2-weighted images.

The presence of a solid component with diffuse contrast enhancement should raise suspicion for secondary $\mathrm{ABC}$, although it might be encountered in the solid variant of ABC.(10)

Therapeutic approaches described in the literature include a combination of curettage, piecemeal excision, en bloc resection, endovascular embolization, intralesional injection of ablating agents and radiation.

In the present case the lesion involved thoracic spine with vertebral body involvement more than the posterior elements which is rare for this disease.

CONCLUSION: Aneurysmal bone cyst is rare disease mainly involving long bones. Spinal involvement is rare and usually involves the posterior elements. Vertebral body involvement more than posterior elements is rare.

\section{REFERENCES:}

1. Papagelopoulos PJ, Currier BL, Shaughnessy WJ, et al. Aneurysmal bone cyst of the spine: management and outcome. Spine 1998; 23 (5): 621-628. 


\section{CASE REPORT}

2. Garneti N, Dunn D, El Gamal E, Williams DA, Nelson IW, Sandemon DR. Cervical spondylop-tosis caused by an aneurysmal bone cyst: a case report. Spine 2003; 28 (4): E68-E70.

3. Fletcher CDM, Unni KK, Mertens F (eds): Pathology and Genetics of Tumours of Soft Tissue and Bone (IARC World Health Organization Classification of Tumours), ed 3. Lyons: IARC Press, pp 338-340, 2006

4. Boriani S, De Iure F, Campanacci L, Gasbarrini A, Bandiera S, Biagini R, et al: Aneurysmal bone cyst of the mobile spine: report on 41 cases. Spine (Phila Pa 1976) 26: 27-35, 2001

5. Cottalorda J, Kohler R, Sales de Gauzy J, Chotel F, Mazda K, Lefort G, et al: Epidemiology of aneurysmal bone cyst in children: a multicenter study and literature review. J Pediatr Orthop B 13:389-394, 2004

6. YOCHUM \& ROWE (2005) ESSENTIALS OF SKELETAL RADIOLOGY, 3rd edn., United States Of America: Lippincott Williams \& Wilkins;page 1295

7. Creager AJ, Madden CR, Bergman S, Geisinger KR. Aneurysmal bone cyst: fine-needle aspiration findings in23 patients with clinical and radiologic correlation. Am J Clin Pathol 2007; 128: 740745.

8. Burch S, Hu S, Berven S. Aneurysmal bone cysts of the spine. Neurosurg Clin N Am 2008; 19: 41-7.

9. Liu JK, Brockmeyer DL, Dailey AT, Schmidt MH. Surgical management of aneurysmal bone cysts of the spine. Neurosurg Focus 2003; 15: E4.

10. Suzuki M, Satoh T, Nishida J, et al. Solid variant of aneurysmal bone cyst of the cervical spine. Spine 2004; 29 (17): E376-E381.
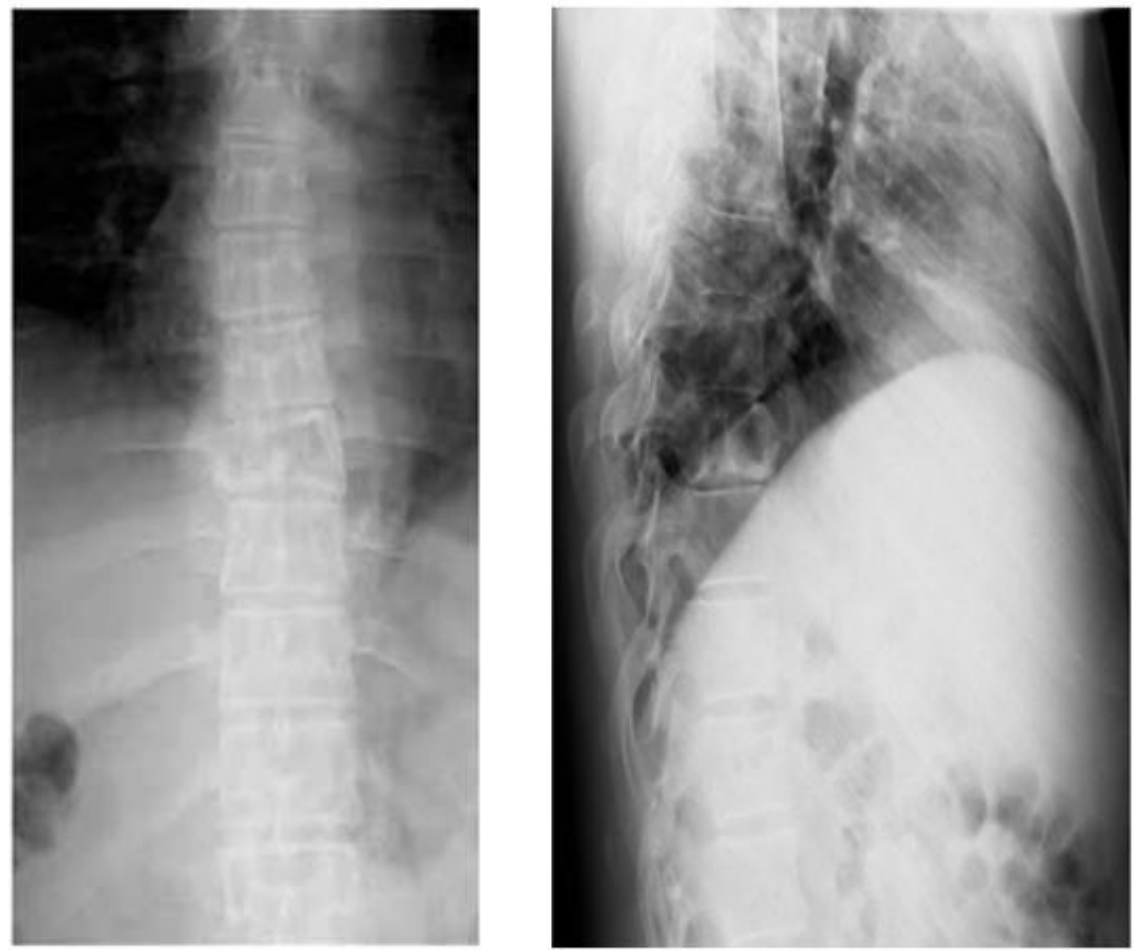

FIG. 1: Expansile lytic lesion at D9 vertebral body with poorly definable right pedicle, reduced intervertebral disc space between D8-D9 and reduction of height of D9 vertebral body. 


\section{CASE REPORT}

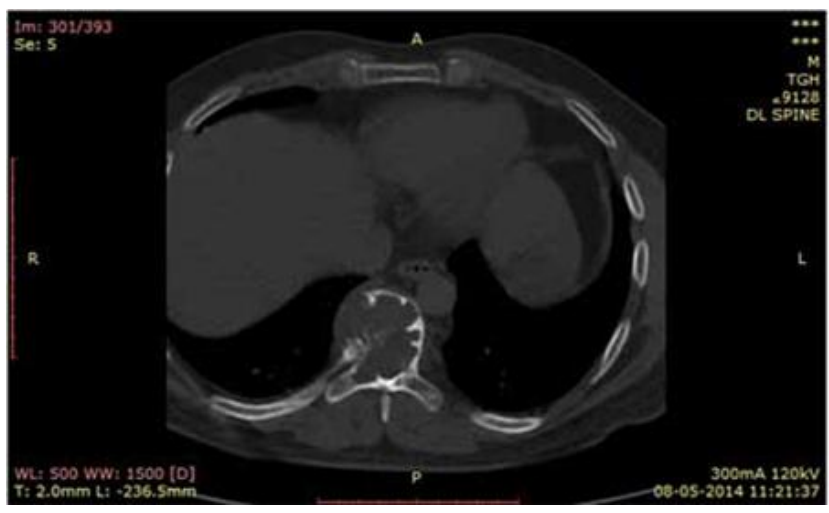

Fig. 2: NECT axial section showing expansile,lytic lesion in D9 vertebral body also extending into bilateral pedicles and right transverse process with thinned out cortex with areas of breach in cortex on right side.

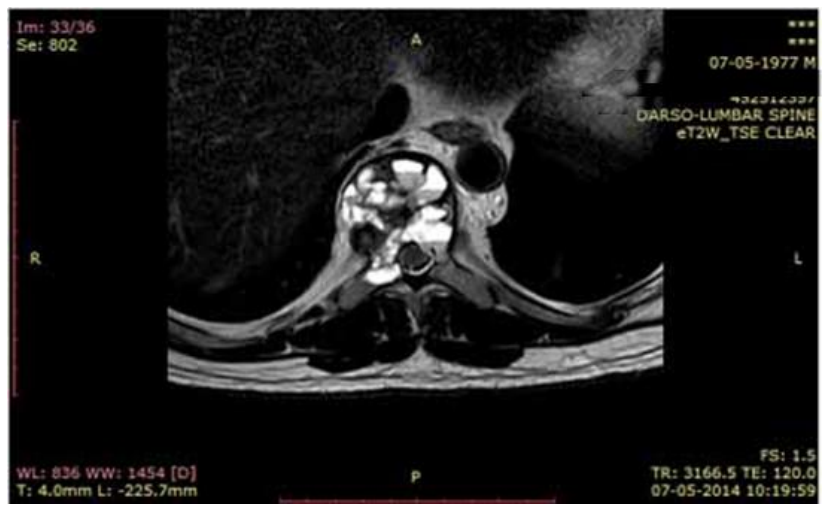

Fig. 3: T2WI Axial section showing hyperintense, expansile, cystic appearing lesion in D9 vertebral body extending into the bilateral pedicles and right transverse process with fluid levels in it.

\section{AUTHORS:}

1. Shrishail Patil

2. Santosh Kumar

3. Sanjeev Chhabra

\section{PARTICULARS OF CONTRIBUTORS:}

1. Associate Professor, Department of Radio-diagnosis, Basaveshwar Teaching and General Hospital, Gulbarga.

2. Post Graduate Student, Department of Radio-diagnosis, Basaveshwar Teaching and General Hospital, Gulbarga.

3. Post Graduate Student, Department of Radio-diagnosis, Basaveshwar Teaching and General Hospital, Gulbarga.

\section{NAME ADDRESS EMAIL ID OF THE CORRESPONDING AUTHOR:}

Dr. Shrishail Patil,

Associate Professor,

H. No. 1, Visheshwarayya Nagar,

Sedam Road, Gulbarga-585105.

E-mail: svbutte@gmail.com

Date of Submission: 25/12/2014.

Date of Peer Review: 26/12/2014.

Date of Acceptance: 16/01/2015.

Date of Publishing: 24/01/2015. 